\title{
Momordica charantia Ameliorates Atopic Dermatitis by Inhibiting the Expression of Inducible Nitric Oxidase Synthase in NC/Nga Mice
}

\author{
Keiichi Hiramoto $^{{ }^{*}}$, Kumi Orita2 ${ }^{2}$, Yurika Yamate1, Hiromi Kobayashi ${ }^{3}$ \\ ${ }^{1}$ Department of Pharmaceutical Sciences, Suzuka University of Medical Science, Suzuka, Japan \\ ${ }^{2}$ Department of Orthopedic Surgery, Osaka City University Graduate School of Medicine, Osaka, Japan \\ ${ }^{3}$ Kobayashi Dermatology Clinic, Nishinomiya, Japan \\ Email: ^hiramoto@suzuka-u.ac.jp
}

How to cite this paper: Hiramoto, K., Orita, K., Yamate, Y. and Kobayashi, H. (2021) Momordica charantia Ameliorates Atopic Dermatitis by Inhibiting the Expression of Inducible Nitric Oxidase Synthase in NC/Nga Mice. Food and Nutrition Sciences, 12, 1136-1151.

https://doi.org/10.4236/fns.2021.1211083

Received: August 24, 2021

Accepted: November 26, 2021

Published: November 29, 2021

Copyright $\odot 2021$ by author(s) and Scientific Research Publishing Inc. This work is licensed under the Creative Commons Attribution International License (CC BY 4.0).

http://creativecommons.org/licenses/by/4.0/

\section{(c) (i) Open Access}

\begin{abstract}
Introduction: Momordica charantia (MC) has been reported to possess various beneficial effects. Improvement in natural aging of the skin has been observed with the use of MC. However, few studies have detailed the effects of $\mathrm{MC}$ on atopic dermatitis (AD). Therefore, in this study, we investigated the effects of MC on the skin symptoms of AD. Methods: Specific pathogen-free and conventional NC/Nga mice were orally administered a $50 \mathrm{mg} / \mathrm{kg} / \mathrm{day}$ dose of MC every day for 2 weeks. Results: The expression levels of lipopolysaccharide (LPS), inducible nitric oxidase synthase (iNOS), and prostaglandin E2 (PGE2) remarkably increased in $\mathrm{AD}$, but were suppressed by MC administration. As a result, the degradation of filaggrin by PGE2 was suppressed. Furthermore, in $\mathrm{AD}$, iNOS induced macrophage type 1 and increased $\mathrm{NO}$ levels. In contrast, due to suppression of iNOS with MC administration, macrophages shifted to type 2 and an increase in L-ornithine was observed, which subsequently promoted filaggrin synthesis. Conclusions: These findings indicate that the $\mathrm{AD}$-like skin symptoms were decelerated by $\mathrm{MC}$ via the regulation of the LPS/iNOS/PGE2/filaggrin and LPS/iNOS/Arginase 1/L-ornithine/ filaggrin signaling pathways.
\end{abstract}

Keywords

Atopic Dermatitis (AD), Momordica charantia (MC), LPS, iNOS, Filaggrin

\section{Introduction}

Common symptoms of atopic dermatitis (AD) include dry, itchy skin, and red 
rashes, particularly in infants and children. $\mathrm{AD}$ is either acute or chronic. Both forms involve thickened skin with an acidic $\mathrm{pH}$, reduced stratum corneum hydration, and elevated transepidermal water loss and erythema index due to changes at the tissue and cellular levels [1]. In 2006, variation in the filaggrin gene was reported to be an important factor for the onset of $\mathrm{AD}$ [2]. Filaggrin is a protein of the horny layer that plays an important role in the skin barrier function. Filaggrin is produced as profilaggrin with a 10 - 12 filaggrin repeat structure. It has a molecular weight of approximately $400 \mathrm{kDa}$ and becomes a $37 \mathrm{kDa}$ filaggrin by the action of various proteases [3] [4]. Meanwhile, filaggrin plays a role in maintaining the strength and plasticity of the horny layer. In the absence of filaggrin, there is an increase in transepidermal water loss (TWEL), and horny cells separate easily [5]. In the crust region of the horny layer, filaggrin is decomposed further and becomes a natural moisturizing factor, such as an amino acid and urocanic acid. In an $\mathrm{AD}$ mouse model, inhibition of filaggrin gene expression was observed, which led to a decrease in skin barrier function. However, skin barrier function can be improved by accelerating the expression of filaggrin [6].

Momordica charantia (MC) is a plant that belongs to the Cucurbitaceae family, which exerts several beneficial effects. It is commonly known as bitter gourd, balsam pear, bitter melon, kugua, or karela [7]. The plant lives up to its common name "bitter melon" or "bitter gourd," as the fruits of the plant have a bitter taste [8] [9]. MC is a traditional herbal medicine that possesses various pharmacological functions, including antidiabetic, abortifacient, anthelmintic, contraceptive, antimalarial, and laxative functions. It is used to treat dysmenorrhea, eczema, gout, jaundice, leprosy, poles, pneumonia, psoriasis, rheumatism, and scabies [10] [11] [12]. Several medicinal properties of MC, including its hypoglycemic, anti-bacterial, anti-viral, anti-tumor, immunomodulatory, anti-oxidant, anti-diabetic, anthelmintic, antimutagenic, antilipolytic, antifertility, hepatoprotective, and anti-inflammatory activities, as well as anti-ulcerogenic, anti-oxidative, and immune-modulatory activities [13] [14] [15], have been studied. We previously reported that natural aging of the skin is ameliorated in MC-administered mice [16]. This effect due to MC administration is induced via the regulation of $17 \beta$-estradiol/mast cell/matrix metalloprotease (MMP)-1/hyaluronidase (HYAL) 2 and testosterone/mast cell/interleukin (IL)-33 signaling pathways. Many studies have demonstrated that MC is a good natural source of antioxidants under experimental conditions; it possesses antioxidant activity in vitro and in vivo [17] [18] [19]. In addition, MC signifies depressed macrophage infiltrators in epicardial adipose tissues (EAT) and brown adipose tissues (BAT) of rats fed a high-fat diet, and downregulated the expression of the pro-inflammatory cytokine, monocyte chemotactic protein-1, tumor necrosis factor (TNF)- $\alpha$ and IL-6 in EAT [20]. Moreover, MC attenuated inflammatory stress in mice with sepsis by reducing the secretion of pro-inflammatory cytokines and the expression of cyclooxygenase (COX)-2, inducible nitric oxide synthase [iNOS], and nuclear factor $[\mathrm{NF}]-\kappa \mathrm{B}$ associated with inflammation [21]. 
Thus, $\mathrm{MC}$ is closely related to inflammation. In $\mathrm{AD}$, inflammatory cytokines, prostaglandin (PGE) 2, COX-2, and reactive oxygen species (ROS) build up the tangle symptoms intricately. However, the influence which exert on the AD of $\mathrm{MC}$ is unclear. Furthermore, the relationship with filaggrin, which is an important onset factor of $\mathrm{AD}$, is unknown. In this study, we orally administered MC to an $\mathrm{AD}$ mouse model and investigated the effect of $\mathrm{MC}$ on $\mathrm{AD}$.

\section{Materials and Methods}

\subsection{Animal Experiments}

Conventional and specific-pathogen-free (SPF) 8-week-old male NC/Nga mice (SLC, Hamamatsu, Shizuoka, Japan) were used. Mice were individually maintained in cages in an air-conditioned room at $23^{\circ} \mathrm{C} \pm 1^{\circ} \mathrm{C}$ with a 12 -h light/12-h dark cycle. SPF mice were maintained under SPF conditions during the experimental procedures. Conventionally maintained mice spontaneously started to exhibit symptoms characteristic of $\mathrm{AD}$ at 7 weeks of age (under uncontrolled, normal maintenance conditions). As expected, all of the conventionally maintained NC/Nga mice used during the experiment exhibited AD-like symptoms that were scored based on severity, including edema, erythema, and hemorrhage ( 0 , none; 1 , slight; 2 , moderate; 3 , severe), as described previously [22]. Mice were divided into the following groups ( $n=6 /$ group): SPF mice, solvent-administered SPF mice, MC-administered SPF mice, conventional mice with $\mathrm{AD}$, solventadministered conventional mice with $\mathrm{AD}$, and $\mathrm{MC}$ administered conventional mice with $\mathrm{AD}$. All mice were examined simultaneously. After administering MC to the mice for 2 weeks, samples were collected on the final day of examination. This study was approved by the Suzuka University of Medical Science Animal Experiment Ethics Committee on September 25, 2014, and was performed in strict accordance with the recommendations of the Guide for the Care and Use of Laboratory Animals of the Suzuka University of Medical Science (Approval number: 34 ). All surgeries were performed under pentobarbital anesthesia, and all efforts were made to minimize animal suffering.

\subsection{Treatment}

The MC fruit extract was provided by ChromaDex, Inc. (Irvine, CA, USA). Approximately $50 \mathrm{mg} / \mathrm{kg}$ body weight of MC in distilled water (DW) was orally administered to mice every day for 2 weeks. The solvent administration group was given distilled water [23].

\subsection{L-NAME Treatment}

Mice were intraperitoneally injected with $20 \mathrm{mg} / \mathrm{kg}$ L-nitro-arginine-methyl ester (L-NAME; antagonist of NOS; Sigma, St Louis, MO, USA) dissolved in $0.1 \mathrm{M}$ phosphate buffer ( $\mathrm{pH}$ 7.2) every day for 2 weeks [24]. The same volume of phosphate buffer was administered to the control group. 


\subsection{Arginase Inhibitor 1 Treatment}

Mice were orally administered $10 \mathrm{mg} / \mathrm{kg}$ arginase inhibitor 1 (Med Chem Express, Monmouth Junction, NJ, USA) dissolved in $0.9 \%$ saline every day for 2 weeks [25]. The same volume of saline was administered to the control group.

\subsection{Preparation and Staining of the Dorsal Skin}

For histological studies, mice were sacrificed 2 weeks after the start of the experiment. Skin specimens were fixed in $4 \%$ phosphate-buffered paraformaldehyde, embedded in frozen Tissue Tek, OCT compound (Sakura Finetek, Tokyo, Japan), and cut into 5- $\mu \mathrm{m}$-thick sections. The presence of filaggrin was immunohistochemically evaluated by staining the specimens with rabbit polyclonal anti-filaggrin (1:100; Covance, Emeryville, CA, USA) primary antibody, as previously described [26]. The specimens were subsequently incubated with a fluorescein isothiocyanate-conjugated anti-rabbit secondary antibody (1:30; Dako Cytomation, Glostrup, Denmark).

\subsection{Western Blotting}

Western blotting was performed as previously described [27]. Briefly, the samples were separated by electrophoresis. Further, the membranes were incubated at $25^{\circ} \mathrm{C}$ for $1 \mathrm{~h}$ with primary antibodies against iNOS (1:1000; Cell Signaling Technology Inc., Danvers, MA, USA), Arginase 1 (1:1000, GeneTex Inc., Hsinchu City, Taiwan), ionized calcium binding adapter protein 1 (Iba1) (marker of macrophage: 1:1000, Wako Pure Chemical Institutes, Ltd., Osaka, Japan), chemokine receptor 7 (CCR7) (marker of M1 macrophage; 1:1000, Abcam, Cambridge, MA, USA), CD163 (M2 macrophage marker; 1:1000, Abcam), or $\beta$-actin (1:5000; Sigma-Aldrich Corp., St. Louis, MO, USA). Immune complexes on the membranes were visualized by incubation with horseradish peroxidase-conjugated secondary antibody (1:1000; Norvex, Frederick, MD, USA) and ImmunoStar Zeta reagent (Wako Pure Chemical Institutes, Ltd.). Images were acquired using the Multi-Gauge Software program (Fujifilm, Greenwood, SC, USA).

\subsection{Measurement of IgE Level in Plasma and LPS, $\mathrm{PGE}_{2}$, COX2, and Nitric Oxide (NO) Levels in the Skin}

The IgE plasma level and $\mathrm{PGE}_{2}$ and COX2 skin levels were determined using a commercial enzyme-linked immunosorbent assay kit (IgE: Yamase Shoyu Co., Chiba, Japan; $\mathrm{PGE}_{2}$ : Enzo Life Sciences Inc., Farmingdale, NY, USA; COX2: Abcam). The levels of LPS and NO in the skin were determined using a commercial assay kit (LPS: GenScript, Piscataway, NJ, USA; NO: BioAssay Systems, Hayward, CA, USA), in accordance with the manufacturer's instructions.

\subsection{L-Ornithine Analysis}

The preparation of amino acid samples for determination in free fractions was performed as described by Muramatsu et al. [28], except that 2\% (w/v) perchloric acid was used for deproteinization instead of $10 \%(\mathrm{w} / \mathrm{v})$ trichloroacetic acid, 
and the supernatant solution was neutralized to $\mathrm{pH} 7.0$ with $5 \mathrm{M} \mathrm{KOH}$. Amino acids in each sample were derivatized according to the method described by Gehrke et al. [29]. The levels of the derivatized amino acids were analyzed using a computer-controlled selected ion monitoring gas-chromatograph mass spectrometer (Shimadzu QP-1000, Shimadzu Co. Ltd., Kyoto, Japan).

\subsection{Statistical Analysis}

All data are presented as the mean \pm standard deviation (SD). The results were analyzed using Microsoft Excel 2010 software (Microsoft Corp., Redmond, WA, USA). Differences between groups were evaluated by one-way ANOVA, followed by Tukey's post-hoc test, using the SPSS version 20 software (SPSS, Inc., Chicago, IL, USA). The results were considered statistically significant at $\mathrm{p}<0.05$.

\section{Results}

\subsection{Effect of MC Treatment on the Severity of AD in NC/Nga Mice}

We first established that AD-like symptoms (edema, erythema, and hemorrhaging) developed in the skin of 9-week-old conventional NC/Nga mice. These ADlike symptoms were improved in conventional NC/Nga mice treated with MC (Figure 1(A) and Figure 1(B)). Blood IgE levels, which are indicators of AD, increased in conventional $\mathrm{NC} / \mathrm{Nga}$ mice but decreased with $\mathrm{MC}$ administration (Figure $1(C)$ ). In SPF mice, no skin symptoms were observed in any group, and no increase in IgE was observed.

\subsection{Effect of MC Treatment on the Skin Levels of LPS, iNOS, PGE and COX2 in NC/Nga Mice}

LPS, iNOS, $\mathrm{PGE}_{2}$, and COX2 levels in the skin were increased in conventional $\mathrm{NC} / \mathrm{Nga}$ mice; however a decrease was observed with $\mathrm{MC}$ administration (Figures 2(A)-(D)). These levels did not change in the skin of SPF mice.

\subsection{Effect of MC Treatment on the Expression of NO, Ornithine, and Arginase I in NC/Nga Mice}

The expression of NO, ornithine, and arginase I was affected by iNOS in the skin. The expression of NO in the skin was increased in conventional NC/Nga mice and a decrease was observed following MC administration (Figure 3(A)). In contrast, the expression of ornithine and arginase I in the skin did not increase in untreated NC/Nga mice; however, an increase was observed upon MC administration (Figure 3(B) and Figure 3(C)). No changes were observed in the expression of ornithine and arginase I in the skin of SPF mice.

\subsection{Effect of MC Treatment on the Expression of Filaggrin in NC/Nga Mice}

The expression of filaggrin in the dorsal skin was remarkably reduced in conventional NC/Nga mice, but it improved by MC administration (Figure 4). There was no change in the expression of filaggrin in the skin of SPF mice. 
(A)
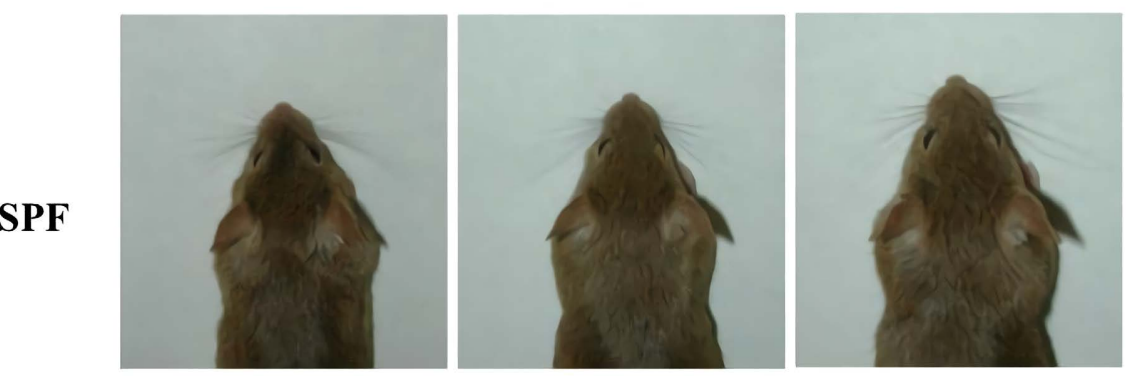

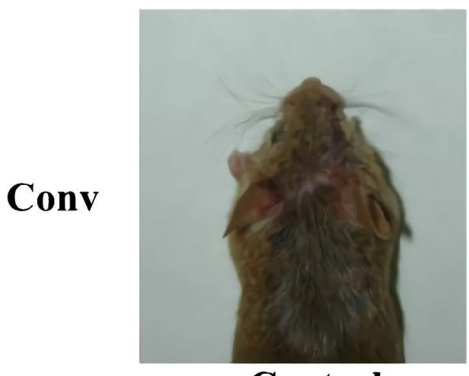

Control

(B)

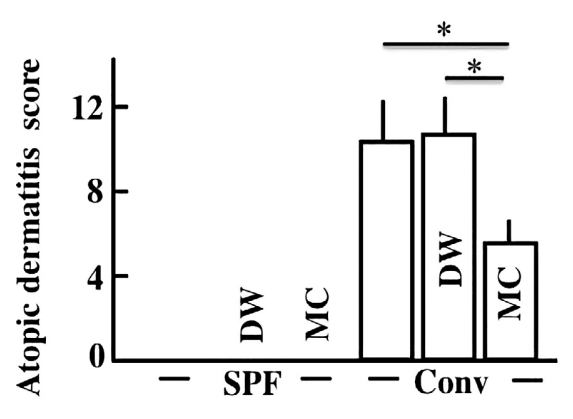

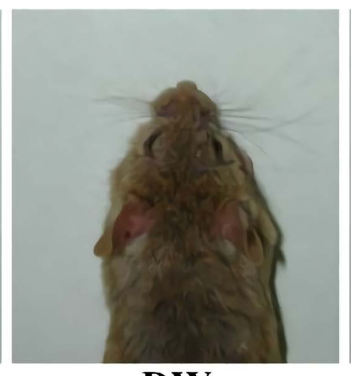

DW

(C)

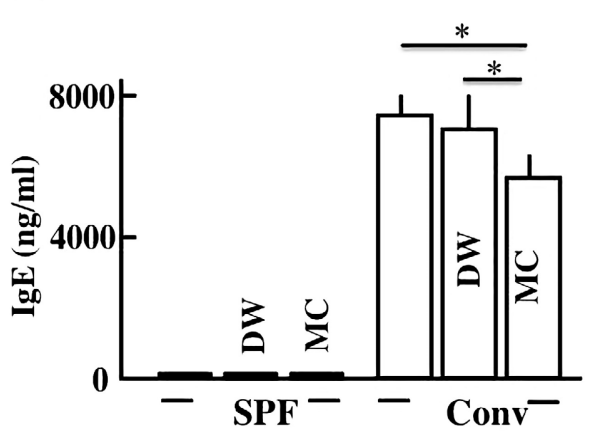

Figure 1. Effects of MC treatment on the skin of NC/Nga mice. (A) Assessment of AD-related skin symptoms, (B) AD score, and (C) plasma level of IgE. MC: Momordica charantia. $\mathrm{DW}$ : distilled water. The values are expressed as mean $\pm \mathrm{SD}$ derived from six animals. ${ }^{\star} \mathrm{P}<$ 0.05 .

(B)
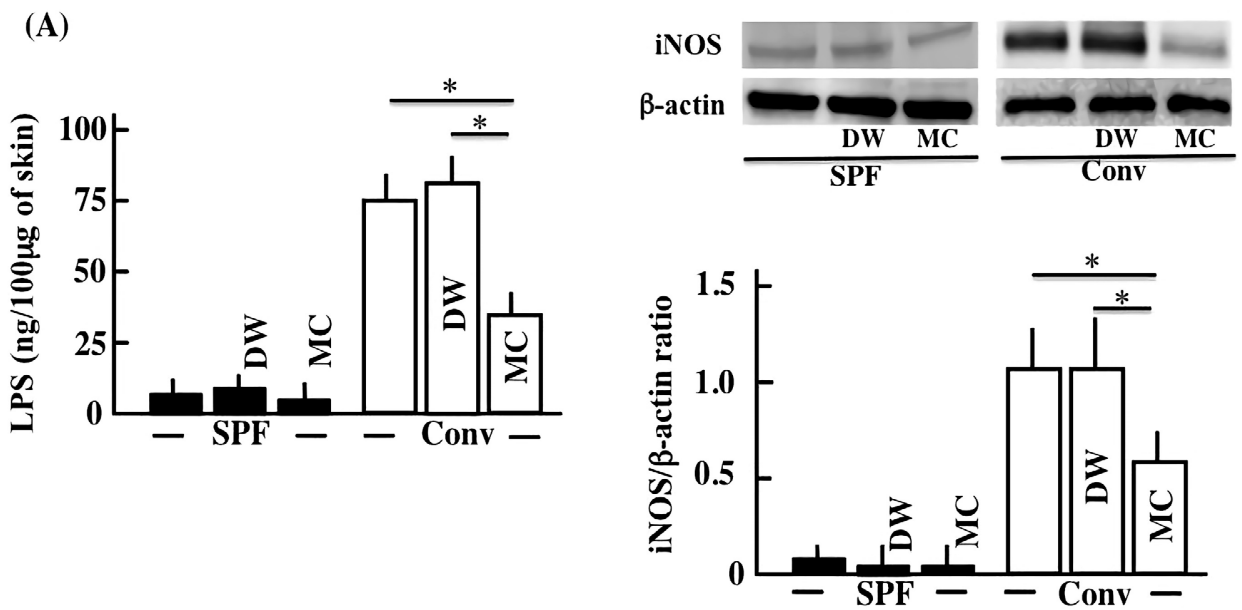
(C)

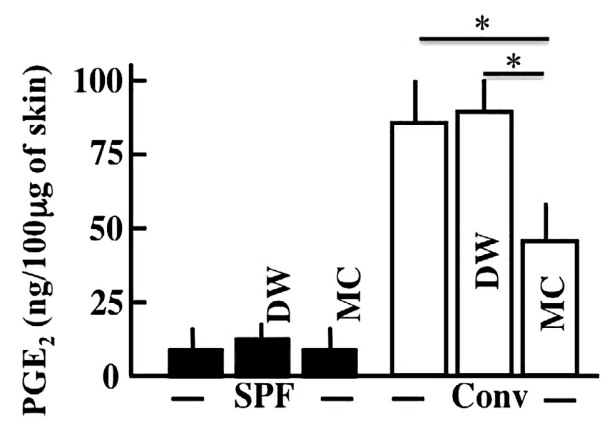

(D)

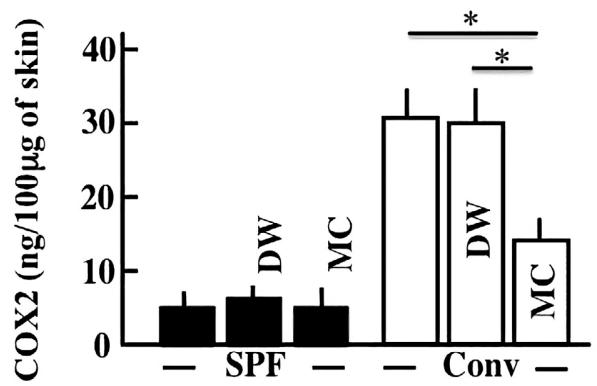

Figure 2. Effects of MC treatment on the skin levels of LPS (A), iNOS (B), PGE2 (C), and COX2 (D) in NC/Nga mice. MC: Momordica charantia. DW: distilled water. The values are expressed as mean \pm SD derived from six animals. ${ }^{*} \mathrm{P}<0.05$.

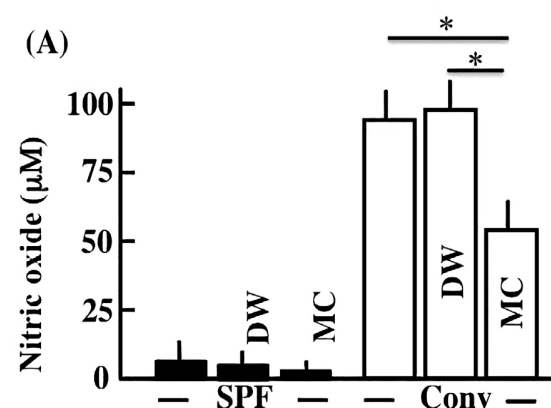

(B)

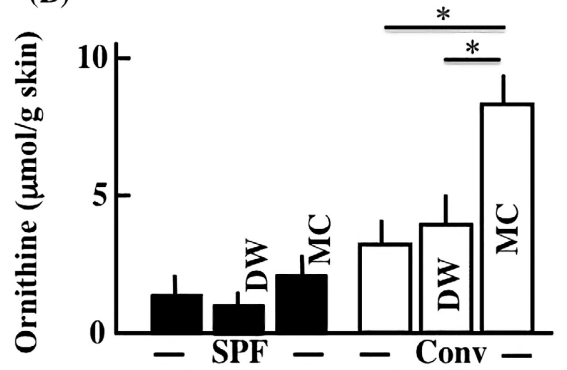

(C)
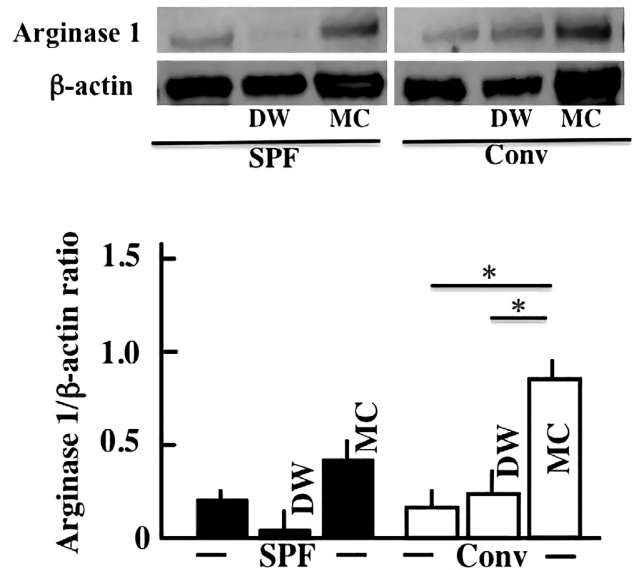

Figure 3. Effects of MC treatment on the skin levels of NO (A), L-ornitine (B), and arginase 1 (C) in NC/Nga mice. MC: Momordica charantia. DW: distilled water. The values are expressed as mean \pm SD derived from six animals. ${ }^{\star} \mathrm{P}<0.05$.

\subsection{Effect of MC Treatment on the Expression of Iba1, CCR7, and CD163 in NC/Nga Mice}

The expression of Ibal (total macrophages) did not differ between the treatment groups (Figure 5(A)). The expression of CCR7 (M1 macrophages) was significantly reduced with the administration of MC (Figure 5(B)). However, a significant increase in CD163 (M2 macrophages) was observed upon MC administration (Figure 5(C)).

\subsection{Effect of L-NAME Treatment on the Severity of AD and the Expression of Filaggrin in NC/Nga Mice}

AD-like symptoms were improved in L-NAME-treated conventional NC/Nga 


\section{Filaggrin}

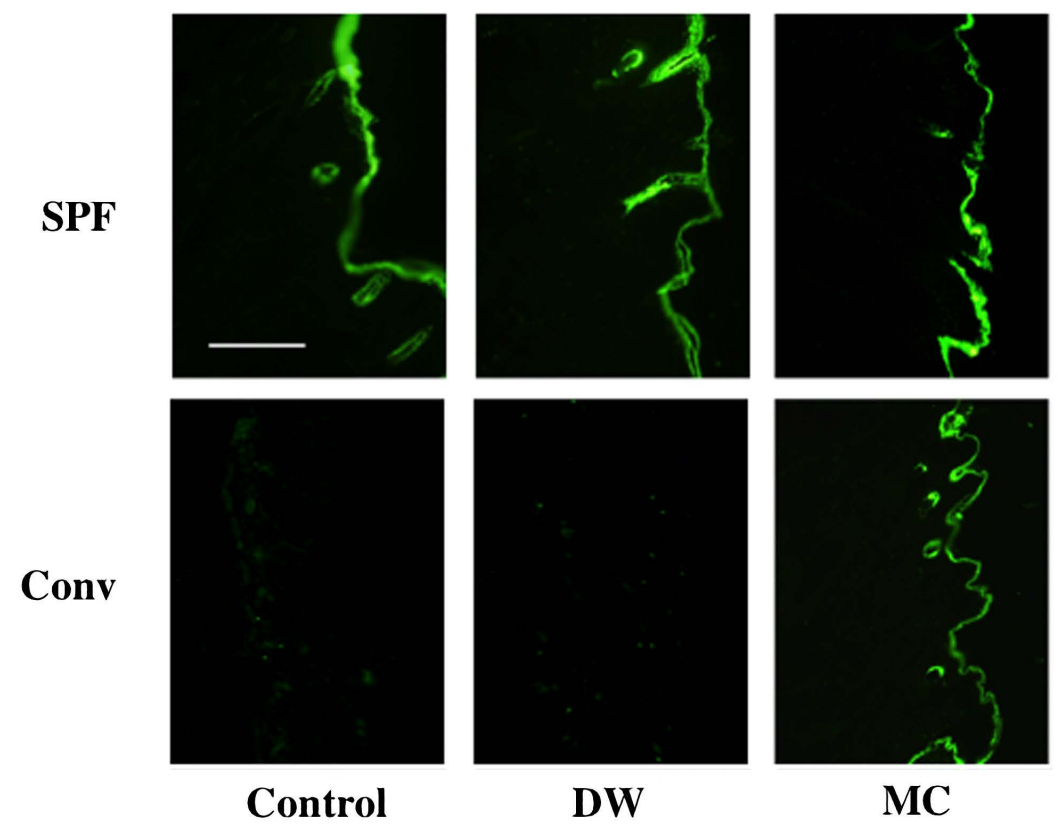

Figure 4. Effects of MC treatment on filaggrin expression in NC/Nga mice. MC: Momordica charantia. DW: distilled water. The data are from one representative experiment conducted with six mice. Scale bar $=100 \mu \mathrm{m}$.

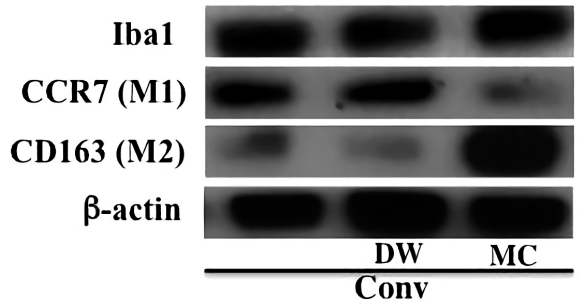

(A)

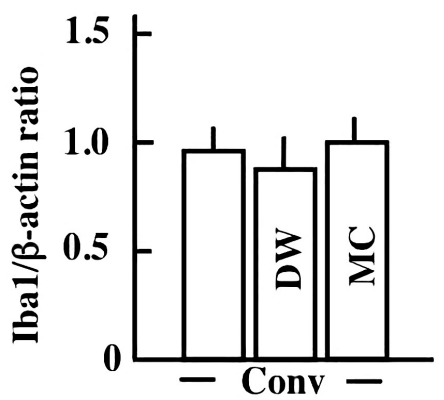

(B)

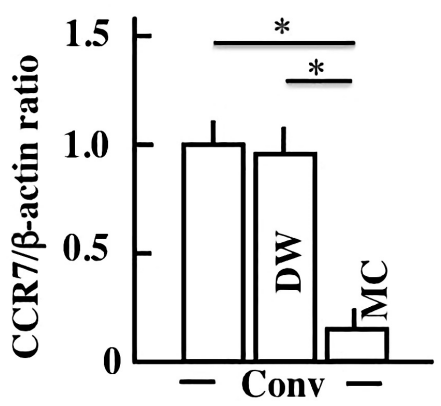

(C)

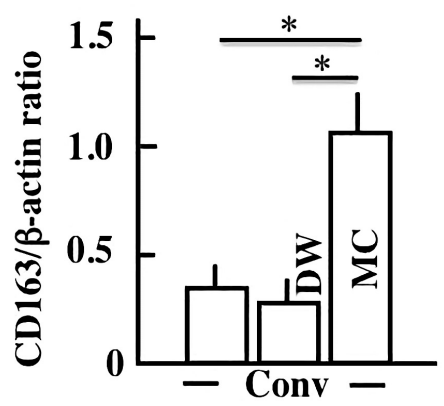

Figure 5. Effects of MC treatment on the expression of Iba1 (A), CCR7 (B), and CD163 (C) in NC/Nga mice. MC: Momordica charantia. DW: distilled water. The values are expressed as mean \pm SD derived from six animals. ${ }^{\star} \mathrm{P}<0.05$.

mice (Figure 6(A)). Further, the expression of filaggrin in the dorsal skin was remarkably reduced in conventional NC/Nga mice; however, an improvement in filaggrin expression was observed upon L-NAME administration (Figure 6(B)). 
(A)
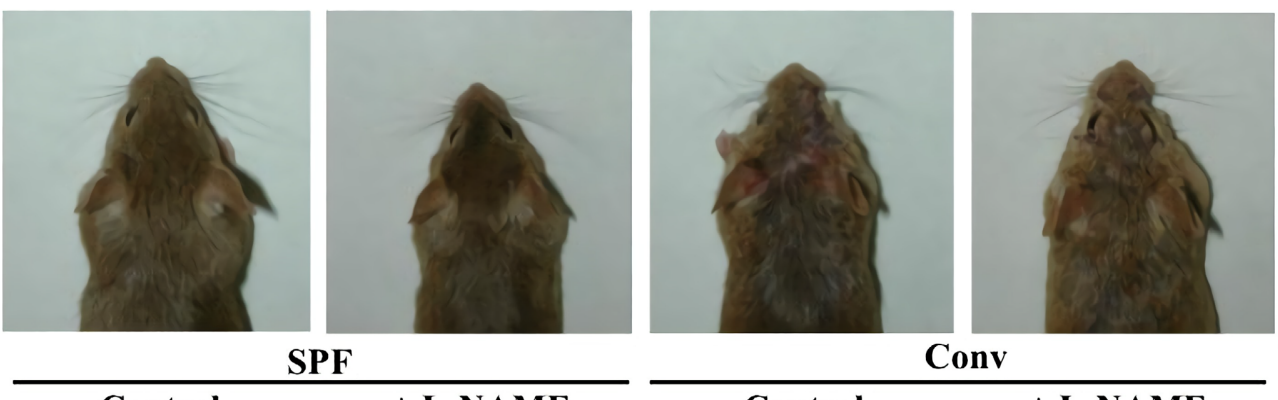

Control

+ L-NAME

Conv

Control + L-NAME

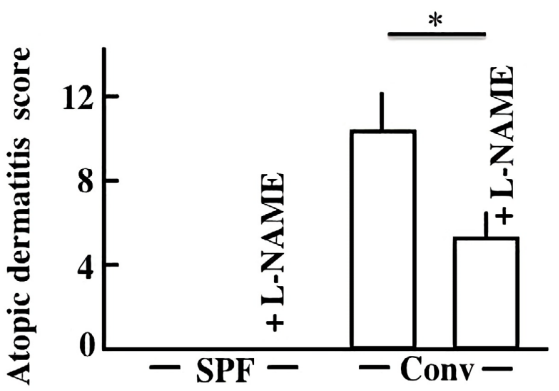

(B)

\section{Filaggrin}

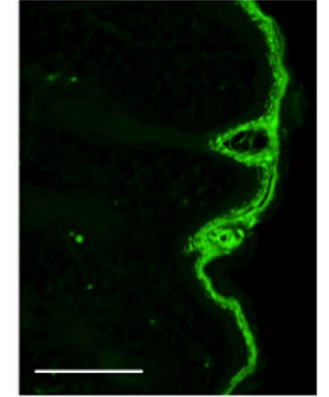

SPF

Control

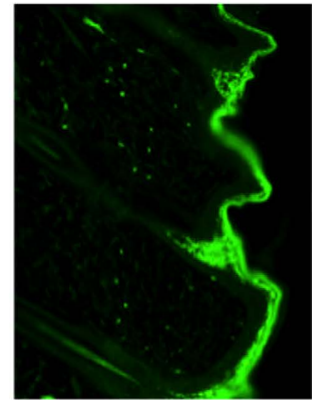

+ L-NAME
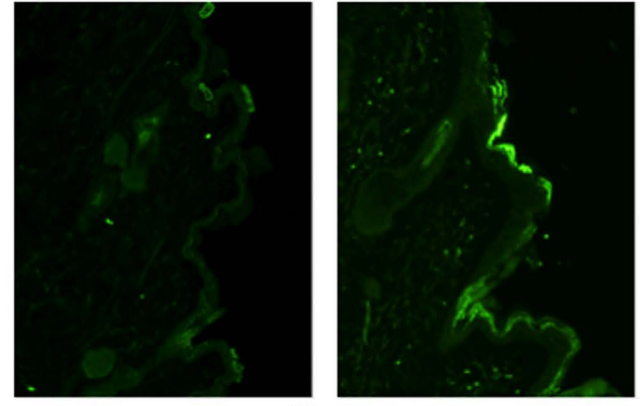

Conv

Figure 6. Effects of L-NAME (antagonist of NOS) treatment on skin symptoms in NC/Nga mice. (A) skin symptoms and $\mathrm{AD}$ score and (B) filaggrin expression in the skin. MC: Momordica charantia. $\mathrm{DW}$ : distilled water. The values are expressed as mean $\pm \mathrm{SD}$ derived from six animals. ${ }^{\star} \mathrm{P}<0.05$. The data are from one representative experiment conducted with six mice. Scale bar $=100 \mu \mathrm{m}$.

\subsection{Effect of Arginase Inhibitor 1 Treatment on the Severity of AD and the Expression of Filaggrin in NC/Nga Mice}

$\mathrm{AD}$-like symptoms were improved with $\mathrm{MC}$ treatment; however, a decrease in the improvement effect was observed with the administration of arginase inhibitor 1 (Figure $7(\mathrm{~A})$ ). The expression of filaggrin in the dorsal skin was increased with MC treatment in conventional NC/Nga mice compared to that in untreated conventional NC/Nga mice; however, a decrease in filaggrin expression was observed upon administration of arginase inhibitor 1 (Figure 7(B)). 
(A)

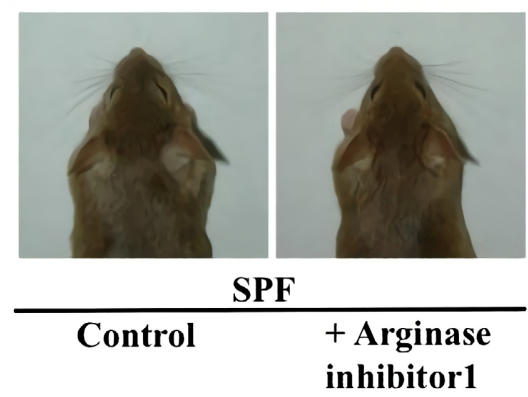

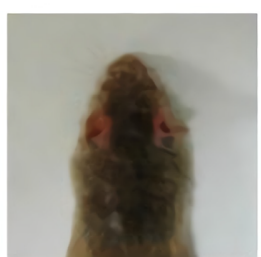

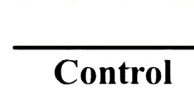

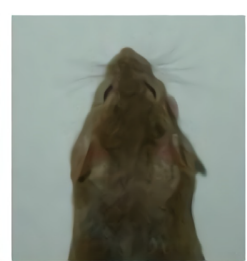

Conv

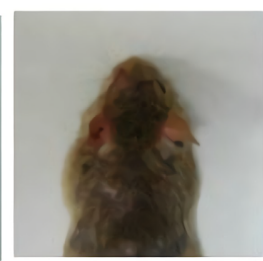

+ Arginase inhibitor 1 $+\mathrm{MC}$

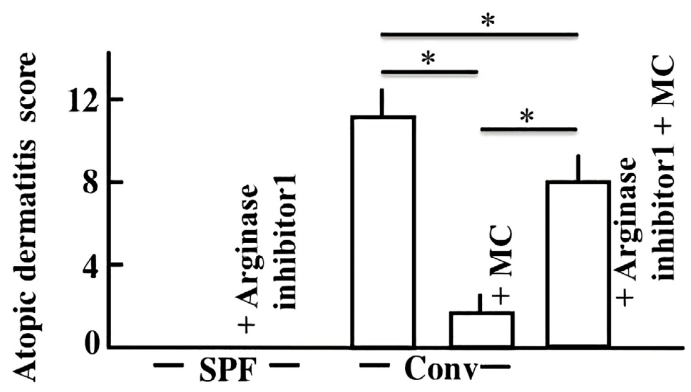

(B)

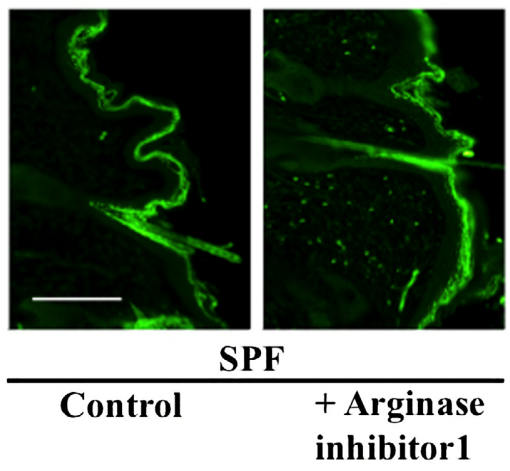

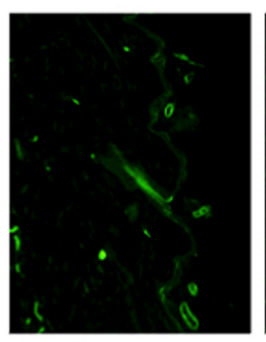

Control

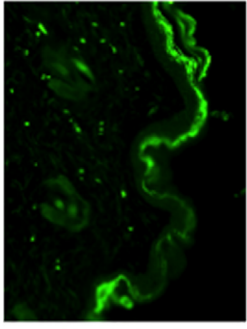

Conv

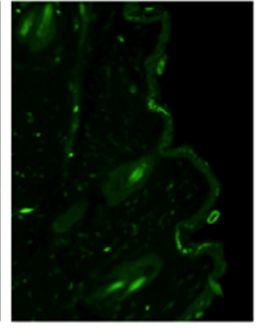

+ Arginase inhibitor 1 $+\mathrm{MC}$

Figure 7. Effects of arginase inhibitor 1 treatment on skin symptoms in NC/Nga mice. (A) skin symptoms and AD score, and (B) filaggrin expression in the skin. MC: Momordica charantia. DW: distilled water. The values are expressed as mean \pm SD derived from six animals. ${ }^{\star} \mathrm{P}<0.05$. The data are from one representative experiment conducted with six mice. Scale bar $=100 \mu \mathrm{m}$.

\section{Discussion}

In this study, MC administration was found to improve $\mathrm{AD}$-like symptoms. An increase was observed in the skin levels of LPS, iNOS, and PGE2 due to AD, which decreased upon MC administration. Furthermore, MC administration decreased NO level in macrophages and conversely increased arginase 1 levels, resulting in an increase in L-ornithine.

$\mathrm{AD}$ is caused by many factors, and recent studies suggest that an allergeninduced immune response is a major cause of $\mathrm{AD}$ [30] [31]. In $\mathrm{AD}$, T cells excessively differentiate into Th2 cells and induce both IgE synthesis and mediate mast cell differentiation through Th2 cytokines [32]. Histamine secreted by mast cells causes itching [33]. Excessive scratching breaks the skin barrier and exposes 
it to external microbes, such as bacteria [34]. LPS present on the outer membrane of gram-negative bacteria acts as an endotoxin and induces the expression of iNOS [35]. INOS increases COX2 expression [36] [37] and PGE2 production [38]. A variety of pro-inflammatory cytokines, including COX2 and PGE2, exert their biological effects through signaling cascades, leading to skin inflammation [39] [40]. Many studies have demonstrated the activation of COX2/PGE2/nuclear factor kappa $\mathrm{B}(\mathrm{NF} \kappa \mathrm{B})$ signaling and the downregulation of filaggrin in the skin of patients with $\mathrm{AD}$ [41] [42] [43]. The present study indicates that MC administration may suppress filaggrin degradation by suppressing the expression of LPS, iNOS, and COX2/PGE2.

Allergens that invade the body are captured by myeloid cells, such as macrophages and dendritic cells. There are two types of macrophages, M1 and M2. M1 type macrophages cause inflammatory cytokine production, tissue damage, and bactericidal action. In contrast, M2-type macrophages contribute to allergic responses, fat metabolism, wound healing, and cancer metastasis [44] [45]. It has been reported that in $\mathrm{AD}$, Ly6c-positive inflammatory monocytes are converted into M2-type macrophages by IL-4 produced by basophils and suppress allergic inflammation [46]. Macrophages activated by allergens release inflammatory cytokines, such as TNF- $\alpha$ and IL- $1 \beta$, as well as inflammatory mediators, such as NO. NO is induced by iNOS when the amino acid, L-arginine, is used as a substrate. M1 macrophages carry out this reaction. In M2-type macrophages, the enzyme, arginase 1, using L-arginine as a substrate, is expressed. INOS and arginase 1 compete for common substrate (L-arginine) utilization [47] [48]. In this study, it was considered that macrophages were converted to the M2 type with

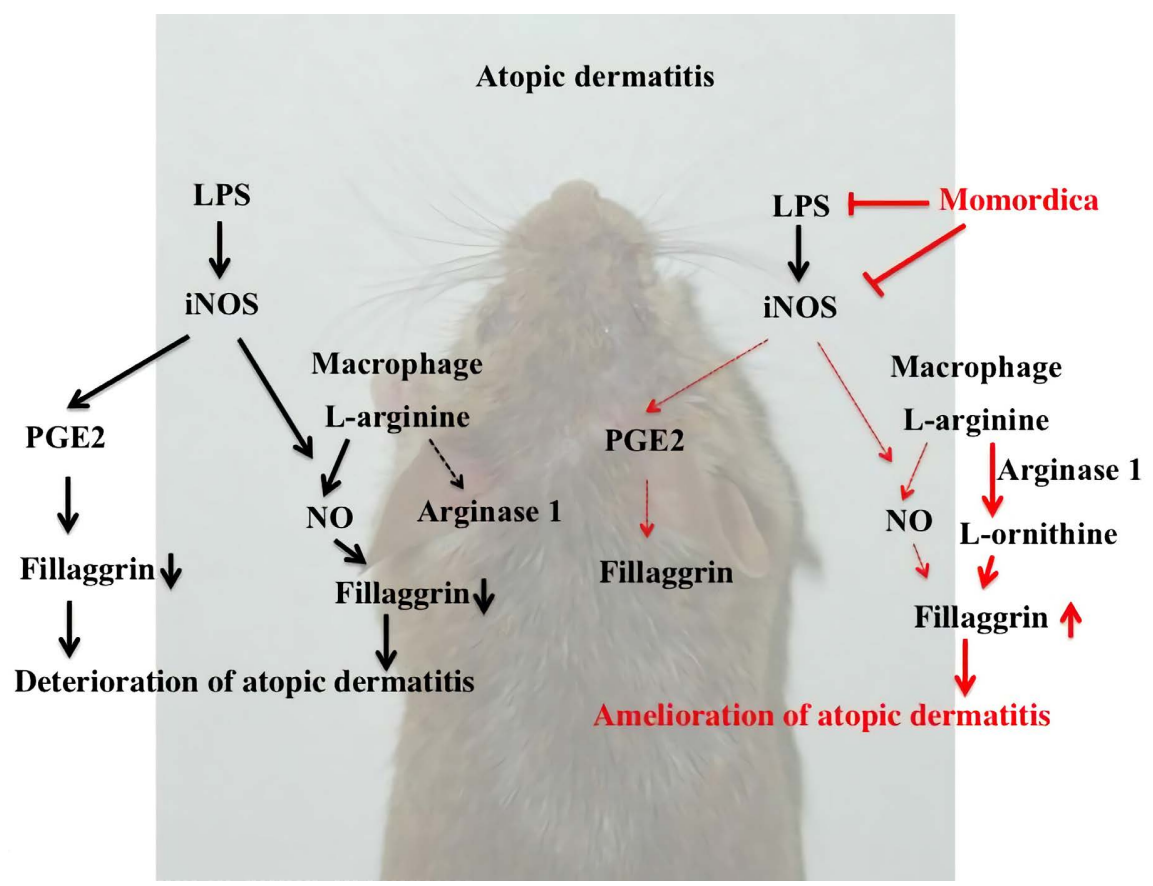

Figure 8. Mechanism of the effect of Momordica charantia on the symptoms of atopic dermatitis. 
the administration of $\mathrm{MC}$, and L-arginine was converted to urea and L-ornithine by the action of arginase 1 . L-ornithine has been reported to promote wound healing and has been known to promote growth hormone secretion and collagen synthesis [49] [50]. In addition, L-ornithine leads to an increase in filaggrin and Natural Moisturizing Factor (NMF) [51] [52]. Thus, the effect of MC induces a decrease in NO synthesis from L-arginine and an increase in arginase 1 by suppressing the increase in iNOS. Arginase 1 was considered to improve AD-like skin symptoms by increasing L-ornithine levels as well as filaggrin synthesis.

\section{Conclusion}

MC improved the skin-related symptoms of AD in mice by suppressing the degradation of filaggrin and promoting its synthesis. Filaggrin degradation was suppressed by downregulating the LPS/iNOS/PGE2 pathway, which is increased by $\mathrm{AD}$. The decrease in iNOS caused macrophages to shift to type 2 , thereby increasing filaggrin expression (Figure 8). However, the mechanism by which MC reduces LPS and iNOS expression is unclear. Of note, this study detailed the role of $\mathrm{MC}$ in $\mathrm{AD}$ model mice. Therefore, it is necessary to further investigate of the role of MCs in AD and carry out clinical studies with patients.

\section{Statement of Ethics}

All experimental procedures described in the present study were conducted in accordance with the recommendations of the Guide for the Care and Use of Laboratory Animals of the Suzuka University of Medical Science (Approval number: 34). All surgeries were performed under pentobarbital anesthesia. Efforts were taken to minimize animal suffering.

\section{Fund}

This study was supported by a JSPS KAKENHI Grant (Number 18K11085).

\section{Conflicts of Interest}

The authors declare no conflicts of interest associated with this study.

\section{References}

[1] Soltanipoor, M.T., Stilla, T., Riethmuller, C., Thyssen, J., Sluiter, J.K., Rustemeyer, T., Fischer, T.W., Kezic, S. and Angelova-Fischer, I. (2018) Specific Barrier Response Profiles after Experimentally Induced Skin Irritant in Vivo. Contact Dermatitis, 79, 59-66. https://doi.org/10.1111/cod.12981

[2] Palmer, C.N.A., Irvine, A.D., Terron-Kwiatkowski, A., Zhao, Y., Liao, H., Lee, S.P., Goudie, D.R., Sandilands, A., Campbell, L.E., Smith, F.J.D., O’Regan, G.M., Watson, R.M., Cecil, J.E., Bale, S.J., Compton, J.G., DiGiovanna, J.J., Fleckman, P., Lewis-Jones, S., Arseculeratne, G., Sergeant, A., Munro, C., Houate, B.E., McElreavey, K., Halkjaer, L.B., Bisgaard, H., Mukhopadhyay, S. and McLean, W.H.I. (2006) Common Loss-of-Function Variants of the Epidermal Barrier Protein Filaggrin Are a Major Predisposing Factor for Atopic Dermatitis. Nature Genetics, 38, 441-446. https://doi.org/10.1038/ng1767 
[3] O’Regan, G.M., Sandilands, A., McLean, W.H. and Irvine, A.D. (2008) Filaggrin in Atopic Dermatitis. Journal of Allergy and Clinical Immunology, 122, 689-693. https://doi.org/10.1016/j.jaci.2008.08.002

[4] O’Regan, G.M. and Irvine, A.D. (2010) The Role of Filaggrin in the Atopic Diathesis. Clinical \& Experimental Allergy, 40, 956-972. https://doi.org/10.1111/j.1365-2222.2010.03522.x

[5] Elias, P.M. and Schmuth, M. (2009) Abnormal Skin Barrier in the Etiopathogenesis of Atopic Dermatitis. Current Opinion in Allergy and Clinical Immunology, 9, 437446. https://doi.org/10.1097/ACI.0b013e32832e7d36

[6] Amano, W., Nakajima, S., Kunugi, H., Numata, Y., Kitoh, A., Egawa, G., Dainichi, T., Honda, T., Otsuka, A., Kimoto, Y., Yamamoto, Y., Tanimoto, A., Matsushita, M., Miyachi, Y. and Kabashima, K. (2015) The Janus Kinase Inhibitor JTE-052 Improves Skin Barrier Function through Suppressing Signal Transducer and Activator of Transcription 3 Signaling. Journal of Allergy and Clinical Immunology, 136, 667677. https://doi.org/10.1016/j.jaci.2015.03.051

[7] Habicht, S.D., Kind, V., Rudloff, S., Borsch, C., Mueller, A.S., Pallauf, J., Yang, R. and Krawinkel, M.B. (2011) Quantification of Antidiabetic Extracts and Compounds in Bitter Gourd Varieties. Food Chemistry, 126, 172-176.

https://doi.org/10.1016/j.foodchem.2010.10.094

[8] Subratty, A.H., Gurib-Fakim, A. and Mahomoodally, F. (2005) Bitter Melon: An Exotic Vegetable with Medicinal Values. Nutrition \& Food Science, 35, 143-147. https://doi.org/10.1108/00346650510594886

[9] Aminah, A. and Anna, P.K. (2011) Influence of Ripening Stages on Physicochemical Characteristics and Antioxidant Properties of Bitter Gourd (Momordica charantia). International Food Research Journal, 18, 895-900.

[10] Bailey, C.J., Day, C. and Leatherdale, B.A. (1986) Traditional Treatments for Diabetes from Asia and the West Indies. Practical Diabetes, 3, 190-192. https://doi.org/10.1002/pdi.1960030406

[11] Roman, A. and Lau, C. (1996) Anti-Diabetic Properties and Phytochemistry of Momordica charantia L (Cucurbitaceae). Phytomedicine, 2, 349-362. https://doi.org/10.1016/S0944-7113(96)80080-8

[12] Dans, A.M.L., Villarruz, M.V.C., Jimeno C.A., Javelosa, M.A.U., Chua, J., Bautista, R. and Velez, G.G.B. (2007) The Effect of Momordica charantia Capsule Preparation on Glycemic Control in Type 2 Diabetes Mellitus Needs Further Studies. Journal of Clinical Epidemiology, 60, 554-559.

https://doi.org/10.1016/j.jclinepi.2006.07.009

[13] Ahmed, I., Adeghate, E., Sharma, A.K., Pallot, D.J. and Singh, J. (1998) Effects of Momordica charantia Fruit Juice on Islet Morphology in the Pancreas of the Streptozotocin-Diabetic Rats. Diabetes Research and Clinical Practice, 40, 145-151. https://doi.org/10.1016/S0168-8227(98)00022-9

[14] Matsuda, M. and DeFronzo, R.A. (1999) Insulin Sensitivity Indices Obtained from Oral Glucose Tolerance Testing: Comparison with the Euglycemic Insulin Clamp. Diabetes Care, 22, 1462-1470. https://doi.org/10.2337/diacare.22.9.1462

[15] Raza, H., Ahmed, I., John, A. and Sharma, A.K. (2000) Modulation of Xenobiotic Metabolism and Oxidative Stress in Chronic Streptozotocin-Induced Diabetic Rats Fed with Momordica charanta Fruit Extract. Journal of Biochemical and Molecular Toxicology, 14, 131-139. https://doi.org/10.1002/(SICI)1099-0461(2000)14:3<131::AID-JBT2>3.0.CO;2-Q

[16] Hiramoto, K., Orita, K., Yamate, Y. and Kobayashi, H. (2020) Role of Momordica 
charantia in Preventing the Natural Aging Process of Skin and Sexual Organs in Mice. Dermatologic Therapy, 33, e14243. https://doi.org/10.1111/dth.14243

[17] Bajpai, M., Pande, A., Tewari, S.K. and Prakash, D. (2005) Phenolic Contents and Antioxidant Activity of Some Food and Medicinal Plants. International Journal of Food Sciences and Nutrition, 56, 287-291. https://doi.org/10.1080/09637480500146606

[18] Liu, C.H., Yen, M.H., Tsang, S.F., Gan, K.H., Hsu, H.Y. and Lin, C.N. (2010) Antioxidant Triterpenoids from the Stems of Momordica charantia. Food Chemistry, 118, 751-756. https://doi.org/10.1016/j.foodchem.2009.05.058

[19] Thenmozhi, A.J. and Subramanian, P. (2011) Antioxidant Potential of Momordica charantia in Ammonium Chloride-Induced Hyperammonemic Rats. Evidence-Based Complementary and Alternative Medicine, 8, 1-7.

https://doi.org/10.1093/ecam/nep227

[20] Bao, B., Chen, Y.G., Zhang, L., Xu, Y.L.N., Wang, X., Liu, J. and Qu, W. (2013) Correction: Momordica charantia (Bitter Melon) Reduces Obesity-Associated Macrophage and Mast Cell Infiltration as Well as Inflammatory Cytokine Expression in Adipose Tissues. PLoS ONE, 8, e84075.

https://doi.org/10.1371/journal.pone.0084075

[21] Chao, C.Y., Sung, P.J., Wang, W.H. and Kuo, Y.H. (2014) Anti-Inflammatory Effect of Momordica charantia in Sepsis Mice. Molecules, 19, 12777-12788. https://doi.org/10.3390/molecules190812777

[22] Dahfen, A., Koch, C., Ernst, D., Schnoller, C., Hartmann, S. and Worm, M. (2008) Systemic PPAR $\gamma$ Ligation Inhibits Allergic Immune Response in the Skin. Journal of Investigative Dermatology, 128, 2211-2218. https://doi.org/10.1038/jid.2008.84

[23] Baek, H.J., Jeong, Y.J., Kwon, J.E. Ra, J.S., Lee, S.R. and Kang, S.C. (2018) Antihyperglycemic and Antilipidemic Effects of the Ethanol Extract Mixture of Ligularia fischeri and Momordica charantia in Type II Diabetes-Mimicking Mice. EvidenceBased Complementary and Alternative Medicine, 2018, Article ID: 3468040. https://doi.org/10.1155/2018/3468040

[24] Imai, A., Nabe, T., Mizutani, N., Sakurai, H., Takenaka, H. and Kohno, S. (2001) Involvement of Nitric Oxide in Pollen-Induced Biphasic Nasal Blockage in Sensitized Guinea Pigs. European Journal of Pharmacology, 423, 63-70. https://doi.org/10.1016/S0014-2999(01)01042-1

[25] Zandt, M.C.V., Whitehouse, D.L., Golebiowski, A., Ji, M.K., Zhang, M., Backett, R.P., Jagdmann, G.E., Ryder, T.R., Sheeler, R., Andreoli, M., Conway, B., Mahboubi, K., D’Angelo, G., Mitschler, A., Cousido-Siah, A., Ruiz, F.X., Howard, E.I., Podjarny, A.D. and Schroeter, H. (2013) Discovery of ${ }^{\circledR}$-2-amino-6-borono-2-(2-(piperidin-1-yl) ethyl) Hexane Acid and Congeners as Highly Potent Inhibitors of Human Arginases I and II for Treatment of Myocardial Reperfusion Injury. Journal of Medicinal Chemistry, 56, 2568-2580. https://doi.org/10.1021/jm400014c

[26] Yokoyama, S., Hiramoto, K., Koyama, M. and Ooi, K. (2014) Skin Disruption Is Associated with Indomethacin-Induced Small Intestine Injury in Mice. Experimental Dermatology, 23, 659-663. https://doi.org/10.1111/exd.12499

[27] Hiramoto, K., Sugiyama, D., Takahashi, Y. and Mafune, E. (2016) The Amelioration Effect of Tranexamic Acid in Wrinkles Induced by Skin Dryness. Biomedicine \& Pharmacotherapy, 80, 16-22. https://doi.org/10.1016/j.biopha.2016.02.013

[28] Muramatsu, T., Salter, D.N. and Coates, M.E. (1985) Protein Turnover of Breast Muscle in Germ-Free and Conventional Chicks. British Journal of Nutrition, 54, 131-145. https://doi.org/10.1079/BJN19850099 
[29] Gehrke, C.W., Roach, D., Zumwalt, R.W., Stalling, L.D. and Wall, L.L. (1968) Quantitative Gas-Liquid Chromatography of Amino Acid in Proteins and Biological Substances. Analytical Biochemistry Laboratories, Inc., Columbia, 27-44.

[30] Park, J.M. and Chae, J.W. (2015) Effects of Aurantii Immaturus Fructus (AI) on Atopic Dermatitis (AD) Induced by DNCB in Mice. Journal of Pediatrics of Korean Medicine, 29, 27-43. https://doi.org/10.7778/jpkm.2015.29.1.027

[31] Lee, D.H., Park, J.K., Choi, J., Jang, H. and Seol, J.W. (2020) Anti-Inflammatory Effects of Natural Flavored Diosmetin in IL-6 and LPS-Induced Macrophage Activation and Atopic Dermatitis Model. International Immunopharmacology, 89, Article ID: 107046. https://doi.org/10.1016/j.intimp.2020.107046

[32] Leung, D.Y. and Soter, N.A. (2001) Cellular and Immunologic Mechanisms in Atopic Dermatitis. Journal of the American Academy of Dermatology, 44, S1-S12. https://doi.org/10.1067/mjd.2001.109815

[33] Hashimoto, Y., Takano, N., Nakamura, A., Nakaike, S., Yu, Z., Endo, Y. and Arai, I. (2004) Scratching Behavior in NC/Nga Mice with Dermatitis: Involvement of Histamine-Induced Itching. Allergology International, 53, 349-358. https://doi.org/10.1111/j.1440-1592.2004.00358.x

[34] Lubbe, J. (2003) Secondary Infections in Patients with Atopic Dermatitis. American Journal of Clinical Dermatology, 4, 641-654. https://doi.org/10.2165/00128071-200304090-00006

[35] Lee, H.J., Jeong, Y.S., Ryu, S.Y. and Ryu, J.H. (1998) Inhibition of Nitric Oxide Synthesis by 8-epi-xanthatin in Activated RAW 264.7 Cells. Yakhak Hoeji, 42, 540-543.

[36] Chen, C.H., Sheu, M.T., Chen, T.F., Wang, Y.C., Hou, W.C., Liu, D.Z., Chung, T.C. and Liang Y.C. (2006) Suppression of Endotoxin-Induced Proinflammatory Responses by Citrus Pectin through Blocking LPS Signaling Pathways. Biochemical Pharmacology, 72, 1001-1009. https://doi.org/10.1016/j.bcp.2006.07.001

[37] Kim, J.B., Han, A.R., Park, E.Y., Kin, J.Y., Cho, W., Lee, J., Seo, E.K. and Lee, K.T. (2007) Inhibition of LPS-Induced iNOS, COX-2 and Cytokines Expression by Poncirin through the NF-kappaB Inactivation in RAW 264.7 Macrophage Cells. Biological and Pharmaceutical Bulletin, 30, 2345-2351.

https://doi.org/10.1248/bpb.30.2345

[38] Lii, C.K., Chen, H.W., Yun, W.T. and Liu, K.L. (2009) Suppressive Effects of Wild Bitter Gourd (Momordica charantia Linn. Var. Abbreviate Ser.) Fruit Extracts on Inflammatory Response in RAW 264.7 Macrophages. Journal of Ethnopharmacology, 122, 227-233. https://doi.org/10.1016/j.jep.2009.01.028

[39] Tsai, M.H., Lin, Z.C., Liang, C.J., Yen, F.L., Chiang, Y.C. and Lee, C.W. (2014) Eupafolin Inhibits PGE2 Production and COX2 Expression in LPS-Stimulated Human Dermal Fibroblasts by Blocking the JNK/AP-1 and Nox2/p47 (phox) Pathways. Toxicology and Applied Pharmacology, 279, 240-251. https://doi.org/10.1016/j.taap.2014.06.012

[40] Xu, W., Hong, S.J., Zeitchek, M., Cooper, G., Jia, S., Xie, P., Qureshi, H.A., Zhong, A., Porterfield, M.D., Galiano, R.D., Surmeier, D.J. and Mustoe, T.A. (2015) Hydration Status Regulates Sodium Flux and Inflammatory Pathways through Epithelial Sodium Channel (ENaC) in the Skin. Journal of Investigative Dermatology, 135, 240-521. https://doi.org/10.1038/jid.2014.477

[41] Tenda, Y., Yamashita, M., Kimura, M.Y., Hasegawa, A., Shimizu, C., Kitajima, M., Onodera, A., Suzuki, A., Seki, N. and Nakayama, T. (2006) Hyperresponsive TH2 Cells with Enhanced Nuclear Factor-Kappa B Activation Induce Atopic Dermatitis-Like Skin Lesions in Nishiki-nezumi Cinnamon/Nagoya Mice. Journal of Allergy 
and Clinical Immunology, 118, 725-733. https://doi.org/10.1016/j.jaci.2006.05.024

[42] Karuppagounder, V., Arumugam, S., Thandavarayan, R.T., Pitchaimani, V., Sreedhar, R., Afrin, R., Harima, M., Suzuki, H., Nomoto, M., Miyashita, S., Suzuki, K., Nakamura, M. and Watanabe, K. (2015) Modulation of HMGB1 Translocation and RAGE/NF $\kappa$ B Cascade by Quercetin Treatment Mitigates Atopic Dermatitis in NC/ Nga Transgenic Mice. Experimental Dermatology, 24, 418-423. https://doi.org/10.1111/exd.12685

[43] Lee, C.W., Lin, Z.C., Hu, S.C.S., Chiang, Y.C., Hsu, L.F., Lin, Y.C., Lee, I.T., Tsai, M.H. and Fang, J.Y. (2016) Urban Particulate Matter down Regulates Filaggrin via COX2 Expression/PGE2 Production Leading to Skin Barrier Dysfunction. Scientific Reports, 6, Article No. 27995. https://doi.org/10.1038/srep27995

[44] Gordon, S. (2003) Alternative Activation of Macrophages. Nature Reviews Immunology, 3, 23-35. https://doi.org/10.1038/nri978

[45] Mantovani, A., Sozzani, S., Locati, M., Allavena, P. and Sica, A. (2002) Macrophage Polarization: Tumor-Associated Macrophages as a Paradigm for Polarized M2 Mononuclear Phagocytes. Trends in Immunology, 23, 549-555. https://doi.org/10.1016/S1471-4906(02)02302-5

[46] Egawa, M., Mukai, K., Yoshikawa, S., Iki, M., Mukaida, N., Kawano, Y., Minegishi, Y. and Karasuyama, H. (2013) Inflammatory Monocytes Recruited to Allergic Skin Acquire an Anti-Inflammatory M2 Phenotype via Basophils-Derived Interleukin-4. Immunity, 38, 570-580. https://doi.org/10.1016/j.immuni.2012.11.014

[47] Kasmi, K.C.E., Qualls, J.E., Pesce, J.T., Smith, A.M., Thompson, R.W., Henao-Tamayo, M., Basaraba, R., Konig, T., Schleicher, U., Koo, M.S., Kaplan, G., Fitzgerald, K.A., Tuomanen, E.I., Orme, I.M., Kanneganti, T.D., Bogdan, C., Wynn, T.A. and Murray, P.J. (2008) Toll-Like Receptor-Induced Arginase 1 in Macrophages Thwarts Effective Immunity against Intracellular Pathogens. Nature Immunology, 9, 1399 1406. https://doi.org/10.1038/ni.1671

[48] Takeda, N., O’Dea, E.L., Doedens, A., Kim, J.W., Weidemann, A., Stockmann, C., Asagiri, M., Simon, M.C., Hoffmann, A. and Johnson, R.S. (2010) Differential Activation and Antagonistic Function of HIF-\{alpha\} Isoforms in Macrophages Are Essential for NO Homeostasis. Genes \& Development, 24, 491-501.

https://doi.org/10.1101/gad.1881410

[49] Bucci, L.R., Hickson, Jr. J.F., Wolinsky, I. and Pivarnik, J.M. (1992) Ornithine Supplementation and Insulin Release in Bodybuilders. International Journal of Sport Nutrition, 2, 287-291. https://doi.org/10.1123/ijsn.2.3.287

[50] Meaume, S., Kerihuel, J.C., Constans, T., Teot, L., Lerebours, E., Kern, J. and Marchasson, I.B. (2009) Efficacy and Safety of Ornithine Alpha-Ketoglutarate in Heel Pressure Ulcers in Elderly Patients: Results of a Randomized Controlled Trial. Journal of Nutrition, Health and Aging, 13, 623-630. https://doi.org/10.1007/s12603-009-0173-Z

[51] Mlitz, V., Latveille, J., Gardinier, S., Jdid, R., Drouault, Y., Hufnagl, P., Eckhart, L. Guinot, C. and Tschachler, E. (2012) Impact of Filaggrin Mutations on Raman Spectra and Biophysical Properties of the Stratum Corneum in Mild to Moderate Atopic Dermatitis. Journal of the European Academy of Dermatology and Venereology, 26, 983-990. https://doi.org/10.1111/j.1468-3083.2011.04198.x

[52] Hoffman, D.R., Kroll, L.M., Basehoar, A., Reece, B., Cunningham, C.T. and Koenig, D.W. (2014) Immediate and Extended Effects of Sodium Lauryl Sulphate Exposure on Stratum Corneum Natural Moisturizing Factor. International Journal of Cosmetic Science, 36, 93-101. https://doi.org/10.1111/ics.12101 